\title{
REVIEW \\ Improvement in Rice Grain Quality by Deep-flood Irrigation and its Underlying Mechanisms
}

\author{
Masahiro CHIBA ${ }^{1 *}$, Tomio TERAO ${ }^{2}$, Hajime WATANABE ${ }^{3}$, \\ Osamu MATSUMURA ${ }^{2}$ and Yoshihiko TAKAHASHI ${ }^{3}$ \\ ${ }^{1}$ Lowland Crops Research Division, Western Region Agricultural Research Center, NARO \\ (Fukuyama, Hiroshima 721-0814, Japan) \\ ${ }^{2}$ Hokuriku Research Center, Central Region Agricultural Research Center, NARO \\ (Joetsu, Niigata 943-0193, Japan) \\ ${ }^{3}$ Graduate School of Science and Technology, Niigata University (Niigata, Niigata 950-2181, Japan)
}

\begin{abstract}
The increased occurrence of chalky rice grains as a result of global warming is becoming a serious problem. The application of deep-flood irrigation (DFI) to a water depth of $18 \mathrm{~cm}$ from the active tillering stage to the maximum tillering stage suppresses the occurrence of chalky grains under both high and normal temperature conditions without decreasing yields. The mechanism by which DFI reduces chalky grains was analyzed relative to carbohydrate supply as carbohydrate deficiencies have been proposed as a cause of chalky grains. DFI suppresses the occurrence of chalky grains due to the increased supply of carbohydrates to the panicles. In paddy fields where a water depth of $18 \mathrm{~cm}$ is not possible, such as in paddy fields with low levees or low water supplies, the combined use of moderate DFI at a water depth of $10 \mathrm{~cm}$ with deep planting can be substituted to produce high-quality rice. DFI did not damage root activity at the ripening stage, even in soils with a low redox potential. Although the DFI treatment slightly decreased the penetration resistance of the soil, the bearing capacity was not affected at the time of combine harvest.
\end{abstract}

Discipline: Crop production

Additional key words: chalky grains, deep planting, high temperature ripening, sink-source

\section{Introduction}

Global warming has caused increases in the average air temperature (ICPP 2013), and higher summer air temperatures may damage the production of crops grown in summer, including rice (Oryza sativa L.). High air temperatures at the flowering stage of rice may cause sterility by inhibiting anther dehiscence (Matsui 2009), thus causing a reduction in grain yield. Grain weight has also been reported to decrease under high temperatures at the ripening stage (Morita et al. 2002); moreover, high temperatures also damage rice grain quality, with high temperature ripening reportedly causing chalky grains (Resurreccion et al. 1977). Chalky grains have a white opaque portion in which carbohydrates have not fully accumulated (Tashiro \& Wardlaw 1991). When the average temperature over 20 days after heading exceeds $26^{\circ} \mathrm{C}$, the occurrence of chalky grains increases (Kondo et al. 2006). Furthermore, high temperatures that occur from 1 to 10 days after heading lead to an increase of cracked grains (Nagata 2004).

Deep-flood irrigation (DFI) is a cultivation method that uses deep water to irrigate a paddy field. DFI can be classified into two major types according to the timing of application and its objectives. The first type is the use of DFI at the reproductive stage to protect pollen formation from cold damage. Low temperatures that occur from the spikelet differentiation stage to the young microspore stage (tetrad stage and early microspore stage) cause serious yield losses due to pollen formation failure (Satake et al. 1987). During these stages, young panicles are still present at the bottom of the stem and may be covered by water at a temperature higher than that of the air during a cool summer if the water is deep enough (Satake et al. 1988). Therefore, DFI is an effective method of preventing yield losses caused by poor pollen formation during cool summers.

The second type is the use of DFI at the vegetative stage, which is currently attracting a great deal of attention, such as in Aichi Prefecture (Aichi Agricultural Research

*Corresponding author: e-mail gadai@affrc.go.jp

Received 25 February 2016; accepted 9 June 2016 
Center 2014), Toyooka City, Hyogo Prefecture (Toyooka City Government), and Shiga Prefecture (Toritsuka et al. 2013). DFI applied at the tillering stage can control the growth of rice plants by suppressing the formation of lateemerging weak tillers (Furuya et al. 1991, Ohe et al. 2010). Weak tillers become inferior stems or eventually die before heading, and a suppression of weak tillers has been shown to improve the sink-source balance (Furuya et al. 1991, Miura et al. 2001, Ohe et al. 2010). Such improvements could reduce the occurrence chalky grains as a poor accumulation of carbohydrates caused by a low source ability to sink is probably a major cause of chalky grains. In this study, we introduce a precise and practical DFI cultivation method for the production of high-quality rice, and assess the potential mechanisms by which DFI suppresses the occurrence of chalky grains.

\section{Water management by deep-flood irrigation}

Fig. 1 shows an example of water management regimes in Niigata, Japan that use DFI and conventional water irrigation (CWI) (Chiba et al. 2009, Chiba et al. 2011b). Rice seedlings were transplanted in the middle of
May under both water management regimes. The fertilization conditions were as follows: basal dressing of $3 \mathrm{~g} \mathrm{~m}^{-2}$ and top dressing at ear formation stage of $2 \mathrm{~g} \mathrm{~m}^{-2}$ in both experiments. Under both CWI and DFI, the water depth in the paddy field was maintained at approximately $4 \mathrm{~cm}$ from seedling transplantation to rooting. After rooting, the water depth was maintained at a low level until midseason drainage under the CWI regime. Intermittent irrigation was subsequently conducted until the end of August. At the beginning of September, the water in the paddy field was drained to prepare for the harvest. However, the water depth in the DFI regime was increased to $18 \mathrm{~cm}$ at the active tilling stage and maintained at that depth until the maximum tillering stage (Fig. 2, Chiba et al. 2009). After the maximum tillering stage, midseason drainage was conducted, followed by intermittent irrigation performed in a similar manner to that for the CWI regime.

\section{Effect of deep-flood irrigation on the growth and yield of rice}

Fig. 3 shows changes in the number of stems under CWI and DFI (Chiba et al. 2009). Under CWI, the number

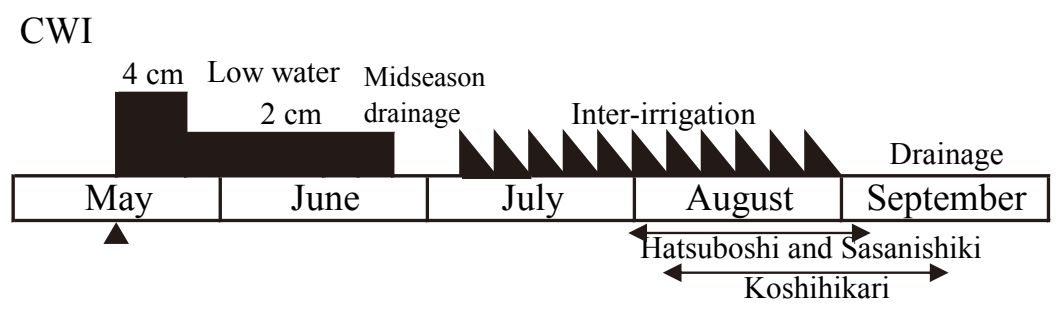

DFI

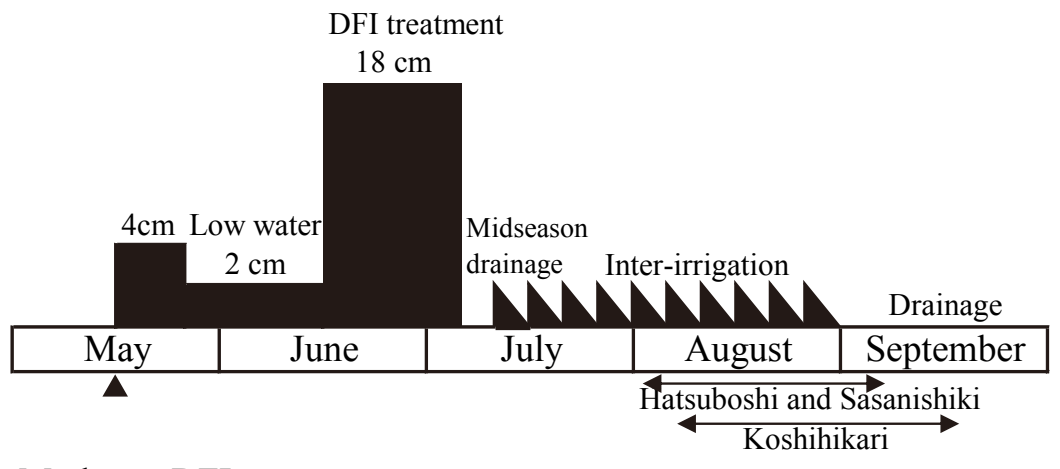

Moderate DFI

Moderate DFI treatment

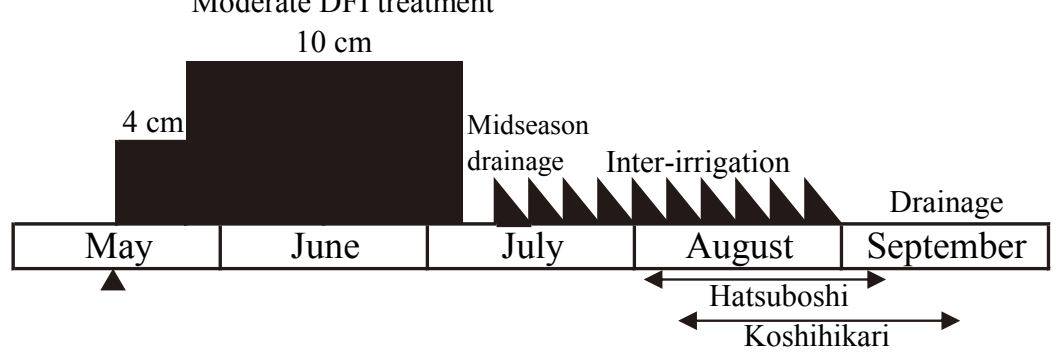

Fig. 1. Schematic diagrams of water management regimes by conventional water irrigation (CWI), deep-flood irrigation (DFI) at a water depth of $18 \mathrm{~cm}$ (from 2004 to 2009) and moderate DFI at a water depth of $10 \mathrm{~cm}$ (from 2008 to 2009).

The arrows indicate the ripening period. Triangles indicate the transplanting time. 
of stems increased until the maximum tillering stage, but decreased thereafter. This change in the number of stems is typical for rice plants grown using conventional cultivation in Japan. However, changes in the number of stems under DFI was different from that under CWI. The DFI treatment completely suppressed the formation of new tillers, none of the emerged tillers died, and almost all of the tillers that emerged prior to DFI treatment produced panicles. Therefore, fewer panicles of an inferior stem, such as secondary tillers or primary tillers from a higher node, were observed under DFI than under CWI. This suppression of tillering and concomitant increase in the percentage of productive stems are consistent with the results from other studies (Furuya et al. 1991, Miura et al. 2001, Ohe et al. 2010).

Decreasing the basal dressing and a deeper placement of the top dressing have reportedly been effective in increasing the percentage of productive stems (Tanaka 1971). However, changes in the number of stems are inconsistent. The number of stems under DFI was established in the early stage and may not change until harvesting, while that for a deeper top dressing, particularly with no basal dressing, may gradually increase until heading (Tanaka 1971). This difference may have caused the difference in tillering pattern (i.e., less emergence of high-order tillers in the late stage under DFI versus late emergence but better development until ripening for the deeper top dressing treatment). The combined use of DFI and a deeper placement of top dressing was not implemented. However, it would be interesting to determine the effect of increasing the percentage of productive stems and the consequent better development of stems and panicles.

The total grain yield under DFI was similar to that under CWI, although the yield components were different (Table 1, Chiba et al. 2009). DFI significantly decreased the

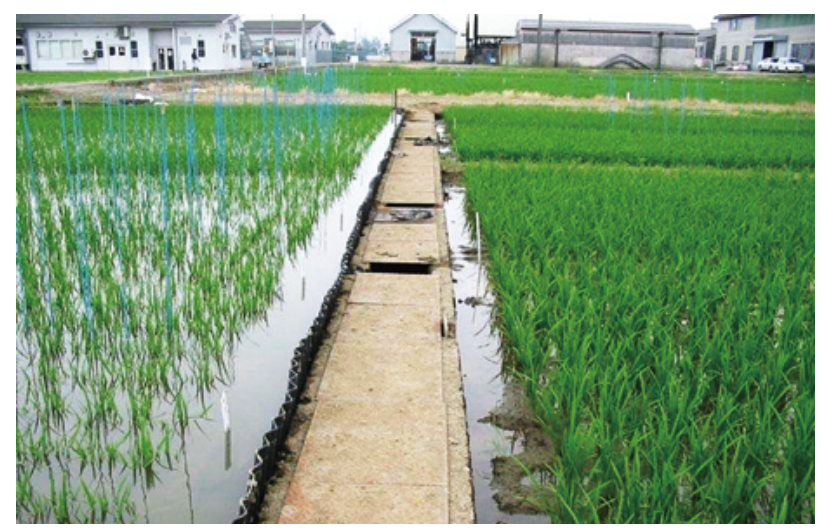

Fig. 2. View of the CWI and DFI treatments at Hokuriku Research Center.

Left to right: DFI and CWI. Abbreviations are the same as in Fig. 1. number of panicles by 10.9 to $19.4 \%$ due to the suppression of tillering, whereas it significantly increased the number of grains per panicle by 8.1 to $16.4 \%$. Thus, the number of grains per panicle appeared to increase as compensation for the decreased number of panicles. Given the increased number of grains, the number of grains per unit area under DFI was only slightly reduced or equivalent to that under CWI. Moreover, the 1000-grain weight increased by 2.4 to $4.7 \%$ under DFI; therefore, the total yield under DFI was not lower than that under CWI.

DFI is a water management process that suppresses the increase in stems to improve grain quality. DFI had no negative effects on yield under the nitrogen applications used in this study. However, DFI appears to not be useful for obtaining high yields because the decreased number of stems/panicles can limit the yield.

\section{Effect of deep-flood irrigation on the quality of rice grains}

We also examined the effect of DFI on the percent occurrence of chalky grains under ambient conditions as well as under a high-temperature treatment, by covering the open top of the chamber just before heading occurred. A field measuring $1.8 \mathrm{~m}$ square was surrounded by plastic film at a height of $1.5 \mathrm{~m}$ in an open-top chamber (Chiba and Terao 2014). The average temperature in the daytime was approximately $0.9^{\circ} \mathrm{C}$ higher in this treatment. DFI decreased the occurrence of chalky grains not only under ambient conditions (rice grown outside of the open-top chamber) but also under high-temperature conditions. Therefore, DFI decreased the percent occurrence of chalky grains in all cultivars, even at high temperatures (Fig. 4). These results show that DFI can reduce the occurrence of chalky grains under a wide range of temperature conditions.

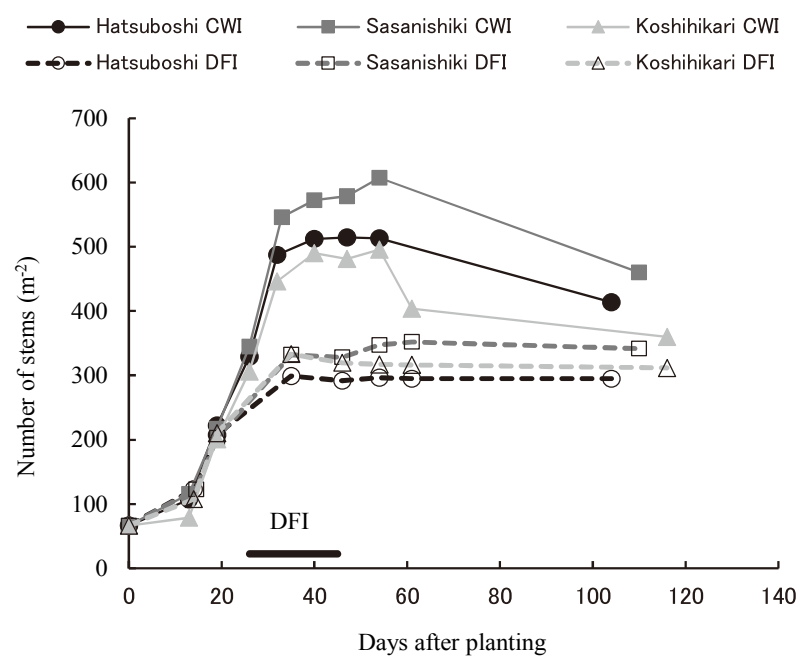

Fig. 3. Changes in the stem number of rice plants under DFI and CWI. 
Table 1. Effect of DFI treatment on the yield and yield components.

\begin{tabular}{|c|c|c|c|c|c|c|c|}
\hline \multirow[t]{2}{*}{ Cultivar } & \multirow[t]{2}{*}{$\begin{array}{c}\text { Water } \\
\text { management }\end{array}$} & \multirow{2}{*}{$\begin{array}{l}\text { Grain yield } \\
\qquad\left(\mathrm{g} \mathrm{m}^{-2)}\right.\end{array}$} & \multirow{2}{*}{$\begin{array}{c}\begin{array}{c}\text { Number of } \\
\text { panicles }\end{array} \\
\left(\mathrm{m}^{-2}\right)\end{array}$} & \multirow[t]{2}{*}{$\begin{array}{c}\text { Number of } \\
\text { grains per } \\
\text { panicle }\end{array}$} & \multirow{2}{*}{$\begin{array}{c}\begin{array}{c}\text { Ripening } \\
\text { percentage }\end{array} \\
(\%) \\
\end{array}$} & \multirow{2}{*}{$\begin{array}{c}\text { 1000-grain } \\
\text { weight }\end{array}$} & \multirow{2}{*}{$\begin{array}{c}\begin{array}{c}\text { Number of } \\
\text { grains per area }\end{array} \\
\left(100 \mathrm{~m}^{-2}\right)\end{array}$} \\
\hline & & & & & & & \\
\hline \multirow[t]{2}{*}{ Hatsuboshi } & CWI & 485 & 381 & 68.8 & 89.4 & 23.0 & 248 \\
\hline & DFI & 463 & 307 & 74.3 & 91.9 & 23.8 & 214 \\
\hline \multirow[t]{2}{*}{ Sasahishiki } & CWI & 504 & 414 & 83.4 & 82.4 & 21.1 & 322 \\
\hline & DFI & 524 & 348 & 97.1 & 87.3 & 22.1 & 313 \\
\hline \multirow[t]{2}{*}{ Koshihikari } & CWI & 497 & 346 & 86.1 & 90.6 & 20.8 & 282 \\
\hline & DFI & 504 & 308 & 96.5 & 89.3 & 21.3 & 282 \\
\hline \multicolumn{2}{|c|}{ Water management } & ns & $*$ & $* *$ & ns & $*$ & ns \\
\hline \multicolumn{2}{|c|}{ Cultivar } & $\mathrm{ns}$ & $* * *$ & $* * *$ & ns & $* * *$ & $* * *$ \\
\hline \multicolumn{2}{|c|}{ Water management $\times$ Cultivar } & ns & ns & ns & ns & ns & ns \\
\hline
\end{tabular}

$*, * *$ and $* * *$ indicate significance at $\mathrm{P}<0.05,0.01$ and 0.001 , respectively. "ns" indicates not significant. The data represent the averages of 3 years in Hatsuboshi and Koshihikari and 2 years in Sasanishiki.

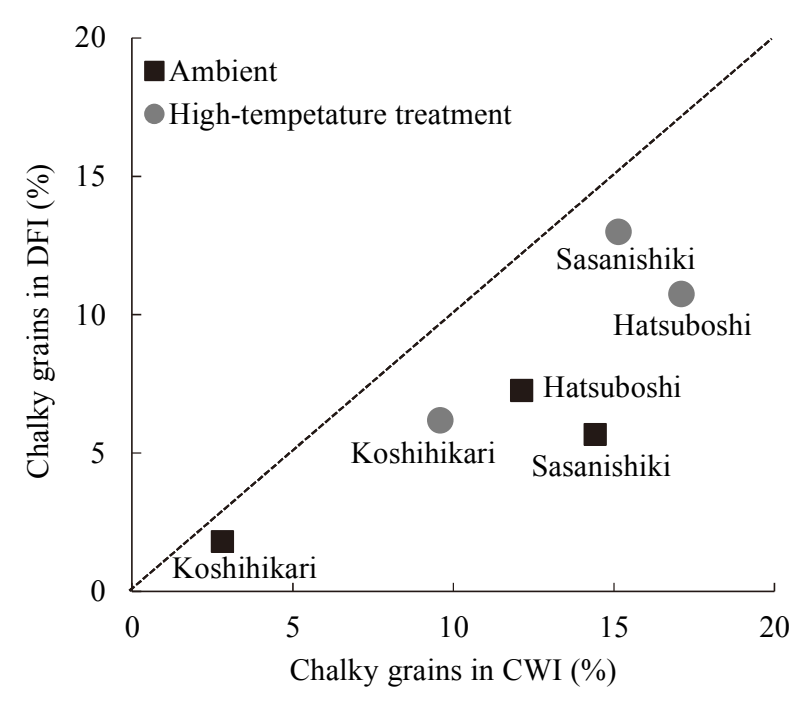

Fig. 4. Effect of DFI on the occurrence of chalky grains. Brown rice samples of more than $1.8 \mathrm{~mm}$ in thickness were investigated with an ES-1000 rice inspector (Shizuoka Seiki Co., Ltd., Shizuoka, Japan). Chalky grains included the total of milky white grains, white belly grains and basal immature grains. The results represent an average of 3 years in Hatsuboshi and Koshihikari and 2 years in Sasanishiki. The percentages of chalky grains under DFI are equal to those under CWI along the dotted line.

\section{Mechanism of high-quality rice production under deep-flood irrigation}

Chalky grains are primarily caused by the insufficient development of starch grains in the endosperm cells
(Tashiro \& Ebata 1975). Assimilated carbohydrates are necessary to fill the starch grains so that gaps do not occur. Carbohydrate shortages cause gaps in the grains, which lead to chalky grains.

There are two major sources of carbohydrates for the panicle: carbohydrates that accumulate in the stem prior to heading, and carbohydrates produced by photosynthesis in the leaves after heading has occurred. The carbohydrates accumulated in the stem were estimated using the amount of nonstructural carbohydrate (NSC) as an indicator, whereas the carbohydrates produced by photosynthesis in the leaves were estimated using the leaf area and nitrogen content of the leaf blade as indicators. These indicators were used to elucidate the mechanisms by which DFI suppresses the occurrence of chalky grains (Chiba et al. 2011a).

First, we analyzed these indicators in all types of stems on a hill under ambient and high temperature conditions. The DFI treatment increased all three indicators and decreased the percentage of chalky grains under the ambient and high-temperature treatments (Fig. 5, Chiba et al. 2011a). These results suggested that both carbohydrate sources (i.e., accumulated in stems and newly assimilated) were increased by the DFI treatment over the entire hill regardless of temperature conditions. This increase in the carbohydrate supply fully filled the endosperm, which inhibited the occurrence of chalky grains. We suggest that this is the principal mechanism by which DFI produces high-quality rice.

The DFI treatment changed the composition of the stems, and the ratio of superior stems that have good ripening characteristics was increased due to the decreased 
A

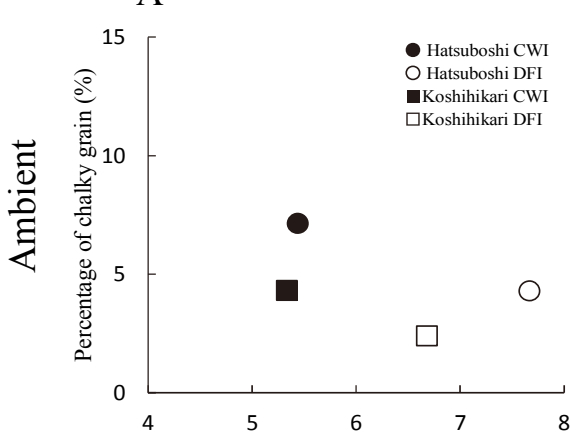

B

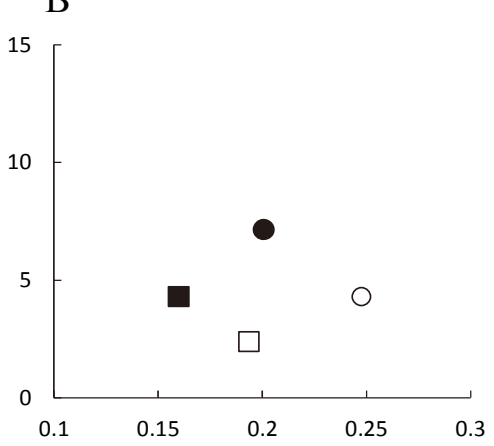

C
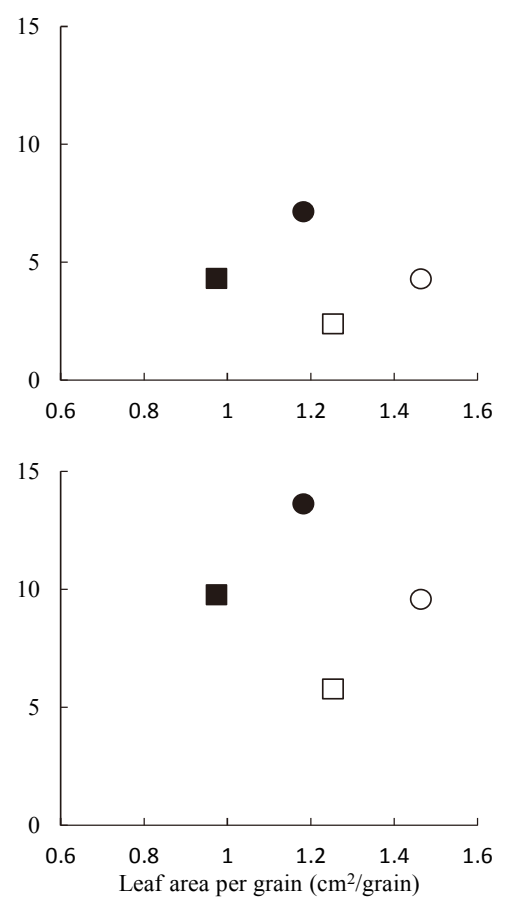

Fig. 5. Relationship between the source ability to the panicle and the chalky grain percentage for the entire hill. A: Stem NSC at the full heading stage, B: Nitrogen in the leaf blade at the full heading stage, C: Leaf area at the middle ripening stage. The data represent an average of 2 years.

number of inferior stems (Chiba et al. 2009). The DFI treatment also decreased the occurrence of chalky grains (Fig. 5). However, it is not clear whether the improved grain quality was caused by improvement in the superior stem ratio or improvement in the source ability to both superior and inferior stems. Therefore, we analyzed the carbohydrate source to the panicle by separating the superior stem (main stem) and inferior stems (highest primary tiller and secondary tiller) obtained under ambient conditions (Fig. 6, Chiba et al. 2013). In this case, little or no secondary tillers were present under DFI; therefore, these data were omitted.

When comparing the effect of DFI in both the main stem and highest primary tiller; we found that the source activity per grain was increased, and the occurrence of chalky grains decreased under the DFI treatment (Fig. 6, Chiba et al. 2013). This result shows that both superior and inferior stems increased the source ability per grain under DFI. Therefore, DFI reduced the occurrence of chalky grains by increasing the source ability of each stem (even in the inferior stems).

When compared with CWI, however, a contradictory phenomenon was observed, particularly in Hatsuboshi. Although the inferior stems had poor source ability compared with the superior stems except for the leaf area in secondary tillers in Hatsuboshi, which should theoretically produce low-quality grains, the percentage of chalky grains in the inferior stems was smaller than that for the superior stems. This could be explained by the percentage of secondary rachis grains that usually have lower grain quality than that of primary rachis grains (Yoshino et al. 2007). The secondary rachis grain percentage in the highest primary tiller was lower than that of the main stem; it was much lower in the secondary tillers, which consequently increased the grain quality (Chiba et al. 2013, data were omitted). The effect of DFI to increase the source ability counters the effect of increasing secondary rachis grains because the increase in grain quality under DFI occurred even when the secondary rachis grains increased (Fig. 6, Chiba et al. 2013).

\section{Improvements via deep-flood irrigation}

High levees in paddy fields are necessary to maintain a water depth of $18 \mathrm{~cm}$ under DFI. Furthermore, a large initial input of water is necessary to increase the water level to $18 \mathrm{~cm}$, although the total water requirements throughout the season for DFI are not much higher than those for CWI (Arita et al. 2006). Consequently, DFI is not possible in all paddy fields. We therefore suggest a modified version of DFI in fields where a water depth of $18 \mathrm{~cm}$ is not possible.

The control of rice plant growth by DFI decreases with decreasing water depth. For example, the percentage of 
A
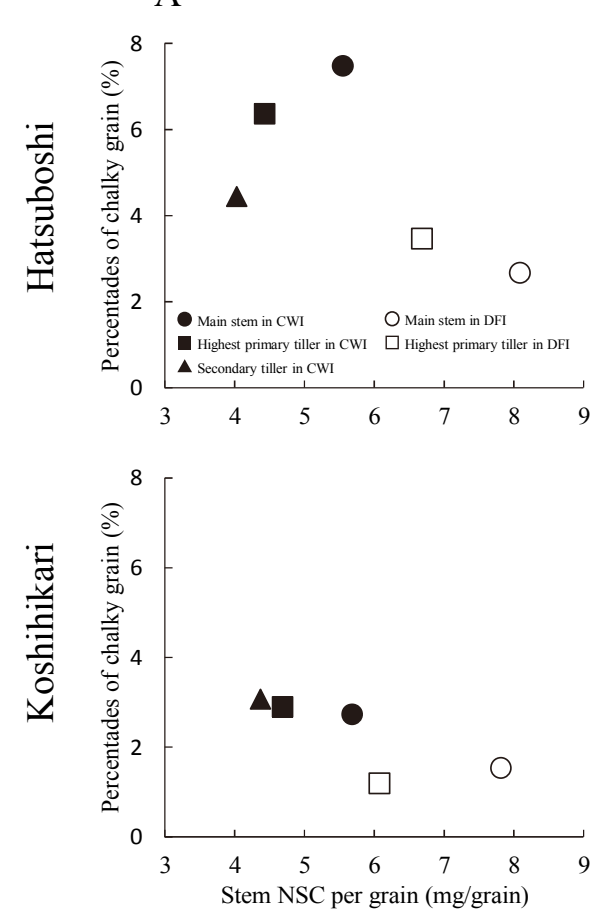

$\mathrm{B}$
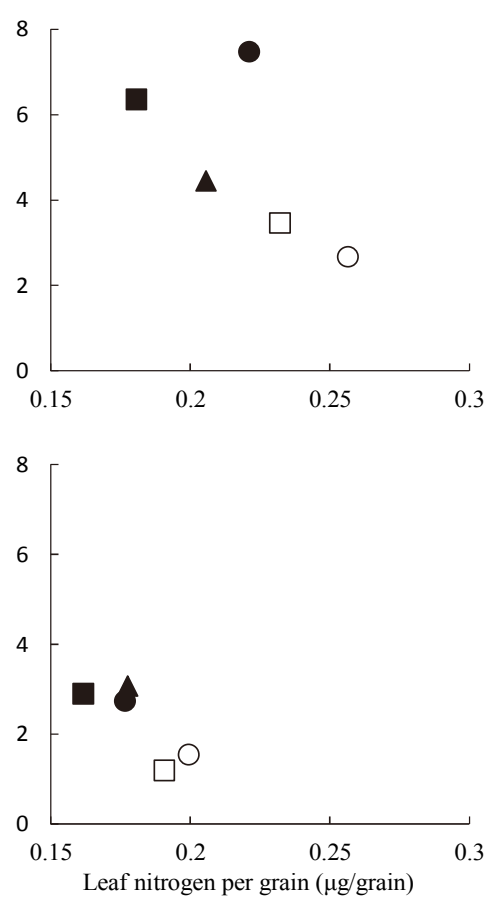

$\mathrm{C}$
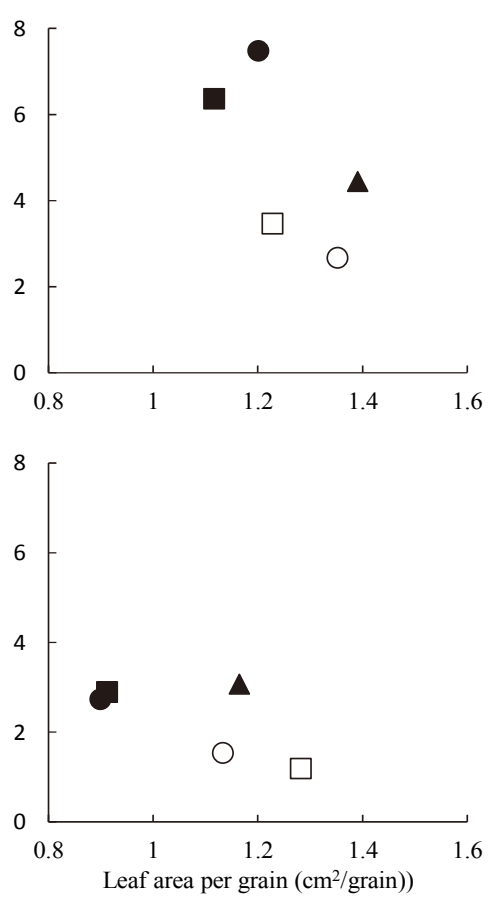

Fig. 6. Relationship between the source ability to the panicle and the chalky grain percentage as determined by the superior and inferior stems sampled under ambient conditions.

A: Stem NSC at the full heading stage, B: nitrogen in the leaf blade at the full heading stage, and C: leaf area at the middle ripening stage. The data represent an average of 2 years.

productive tillers was lower when the water depth was less than $18 \mathrm{~cm}$ (Fig. 7). At a water depth of $18 \mathrm{~cm}$, the percentage of productive tillers was $100 \%$ in Hatsuboshi and nearly $100 \%$ in Koshihikari. Similar results were obtained for water depths as low as $15 \mathrm{~cm}$; therefore, a reduction in water depth to $15 \mathrm{~cm}$ might be sufficient for DFI, although $15 \mathrm{~cm}$ may still be a difficult depth to maintain. At a water depth of approximately $10 \mathrm{~cm}$, the percentage of productive tillers was decreased to approximately $90 \%$ in Hatsuboshi and less than $80 \%$ in Koshihikari.

Deep planting is another method of suppressing tiller emergence (Ito et al. 1970, Saito 1994). Although deep planting is not recommended in certain prefectures (Department of Agriculture, Forestry and Fisheries, Niigata Prefectural Government, 2005; Department of Agriculture, Forestry and Fisheries, Shimane Prefectural Government, 2015), only small reductions in yield were observed when the planting depth was within the adjustable range of a transplanting machine (usually $5 \mathrm{~cm}$ ) (Chiba et al. 2011b). Accordingly, the combined use of moderate DFI (at a water depth of $10 \mathrm{~cm}$ ) and adjustment of the deepest planting depth using machine planting might provide an alternative to DFI at $18 \mathrm{~cm}$ (Chiba et al. 2011b).

We implemented moderate DFI at a water depth of $10 \mathrm{~cm}$ at the rooting stage and drained the paddy at the maximum tillering stage (Fig. 1). This moderate DFI was combined with deep planting $(6 \mathrm{~cm})$ and normal-depth planting $(3 \mathrm{~cm})$. Because we manually transplanted the mid-sized seedlings but not the young seedlings planted by machine, the depth of deep planting in this experiment was $6 \mathrm{~cm}$, and thus larger than the maximum depth of a common transplanting machine $(5 \mathrm{~cm})$.

The moderate DFI treatment and deep planting individually suppressed increases in the number of stems, although the effect was weaker than that under the DFI treatment at $18 \mathrm{~cm}$ (Fig. 8, Chiba et al. 2011b). However, the combined use of moderate DFI treatment and deep planting showed a greater suppression of the number of stems (Fig. 8), which consequently decreased the number of panicles and increased the grains per panicle (Table 2, Chiba et al. 2011b). Therefore, the combination of moderate DFI and deep planting had an additive effect on increases in panicle weight as compared with each separate effect. As decreases in the number of panicles are compensated for by increases in the number of grains per panicle, the number of grains per unit area was unaffected by either water management or planting depth. Therefore, moderate DFI and deep planting did not change the grain yield at our applied nitrogen level. However, deep planting slightly delayed initial growth (Fig. 8), which might limit the yield, 


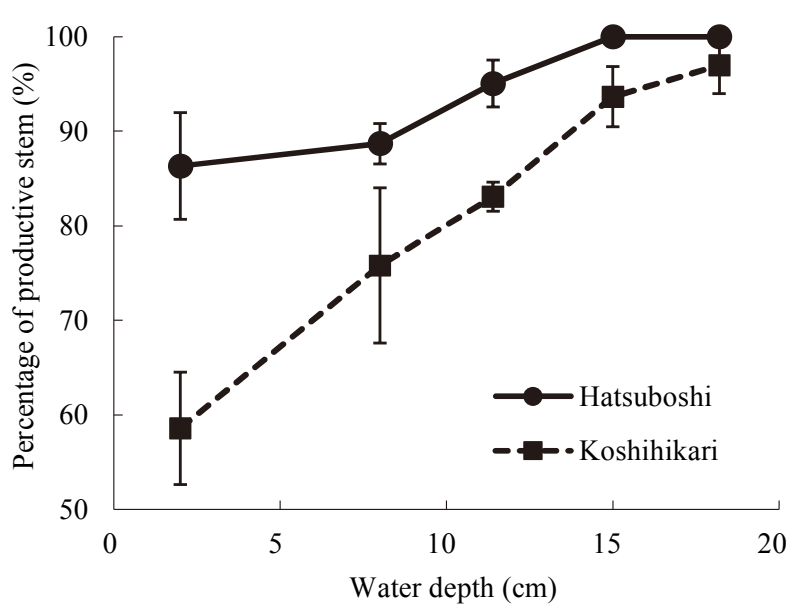

Fig. 7. Effect of the irrigation water depth on the availability of stems $(\%)$ that can bear panicles.

The error bars represent the standard error.

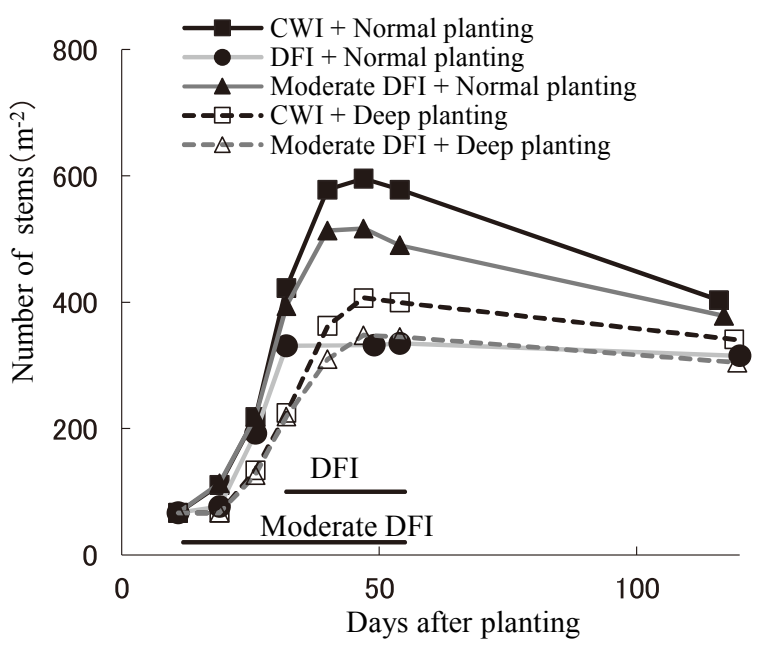

Fig. 8. Effect of the water management regime and planting depth on changes in the number of stems during the growth stages.

Table 2. Effect of moderate DFI treatment and deep planting on the yield and yield components.

\begin{tabular}{|c|c|c|c|c|c|c|c|c|}
\hline \multirow[t]{2}{*}{ Cultivar } & \multirow[t]{2}{*}{$\begin{array}{c}\text { Water } \\
\text { management }\end{array}$} & \multirow[t]{2}{*}{ Planting depth } & \multirow{2}{*}{$\begin{array}{c}\text { Grain yield } \\
\frac{\left(\mathrm{g} \mathrm{m}^{-2}\right)}{}\end{array}$} & \multirow{2}{*}{$\begin{array}{c}\begin{array}{c}\text { Number of } \\
\text { panicles }\end{array} \\
\left(\mathrm{m}^{-2}\right)\end{array}$} & \multirow[t]{2}{*}{$\begin{array}{l}\text { Number of } \\
\text { grains per } \\
\text { panicle }\end{array}$} & \multirow{2}{*}{$\begin{array}{c}\begin{array}{c}\text { Ripening } \\
\text { percentage }\end{array} \\
(\%) \\
\end{array}$} & \multirow{2}{*}{$\begin{array}{c}\text { 1000-grain } \\
\text { weight }\end{array}$} & \multirow{2}{*}{$\begin{array}{c}\begin{array}{c}\text { Number } \\
\text { of grains } \\
\text { per area }\end{array} \\
\left(100 \mathrm{~m}^{-2}\right)\end{array}$} \\
\hline & & & & & & & & \\
\hline \multirow[t]{4}{*}{ Hatsuboshi } & CWI & Normal & 595 & 425 & 67.0 & 91.9 & 22.8 & 284 \\
\hline & & Deep & 601 & 395 & 73.6 & 91.7 & 22.5 & 291 \\
\hline & Moderate DFI & Normal & 587 & 387 & 71.6 & 93.0 & 22.8 & 277 \\
\hline & & Deep & 585 & 348 & 81.5 & 91.4 & 23.0 & 282 \\
\hline \multirow[t]{4}{*}{ Koshihikari } & CWI & Normal & 596 & 383 & 81.4 & 87.3 & 22.0 & 311 \\
\hline & & Deep & 603 & 353 & 90.0 & 85.8 & 22.2 & 317 \\
\hline & Moderate DFI & Normal & 589 & 364 & 85.3 & 86.1 & 22.1 & 309 \\
\hline & & Deep & 594 & 319 & 97.2 & 86.5 & 22.4 & 307 \\
\hline \multicolumn{3}{|c|}{ Planting depth } & $\mathrm{ns}$ & $*$ & $* * *$ & ns & ns & ns \\
\hline \multicolumn{3}{|c|}{ Water management } & ns & $*$ & $* * *$ & ns & ns & ns \\
\hline \multicolumn{3}{|c|}{ Cultivar } & $\mathrm{ns}$ & $*$ & $* * *$ & $* *$ & $* * *$ & $* *$ \\
\hline \multicolumn{3}{|c|}{ Planting depth $\times$ Cultivar } & ns & ns & ns & ns & ns & ns \\
\hline \multicolumn{3}{|c|}{ Planting depth $\times$ Water management } & ns & ns & ns & ns & ns & ns \\
\hline \multicolumn{3}{|c|}{ Water management $\times$ Cultivar } & ns & ns & ns & $\mathrm{ns}$ & ns & ns \\
\hline
\end{tabular}

$*, * *$ and $* * *$ indicate significance at $\mathrm{P}<0.05,0.01$ and 0.001 , respectively. "ns" indicates not significant. The data represent the averages of 2 years.

and earlier transplanting could provide a method of obtaining sufficient panicles if retarded growth poses a problem.

Fig. 9 shows the effect of these alternative methods on the percentage of chalky grains (Chiba et al. 2011b).
Moderate DFI and deep planting individually reduced the occurrence of chalky grains, although the reduction was less than that under DFI. The suppression of chalky grains in the combined use of moderate DFI and deep planting 
treatment was larger than that in either individual treatment and comparable to that under DFI in certain cases.

We therefore recommend the combined use of moderate DFI and deep planting as a cultivation method in paddy fields where DFI cannot be introduced due to the levee height.

\section{Effect of deep flood irrigation on root activity and the bearing capacity of soil}

Rice farmers might wonder whether DFI will cause the soil to become too highly reduced as DFI has been shown to decrease the soil redox potential (Chiba et al. 2011b, Furuya et al. 1991). A low redox potential in soil is known to cause serious damage to rice plant roots. Therefore, we investigated the effect of DFI on root activity by measuring the rate of bleeding from newly cut sections of stems on a hill as a putative index of root activity (Morita 1999). At the full heading stage, significant differences in the bleeding rate were not observed between the DFI and CWI treatments (Fig. 10, Chiba et al. 2011b). At the middle ripening stage, the bleeding rate under DFI was not reduced compared to that under CWI and was even higher under certain conditions. Although the soil redox potential was lowered under DFI, decreases in the bleeding rate were not observed, which likely indicated no decrease in root activity. Therefore, DFI likely does not damage the rice plant roots, even under conditions with a low redox potential.

Another issue with implementing DFI is the possibility that DFI might reduce the soil bearing capacity at harvest because the soil moisture level might still be high. There-

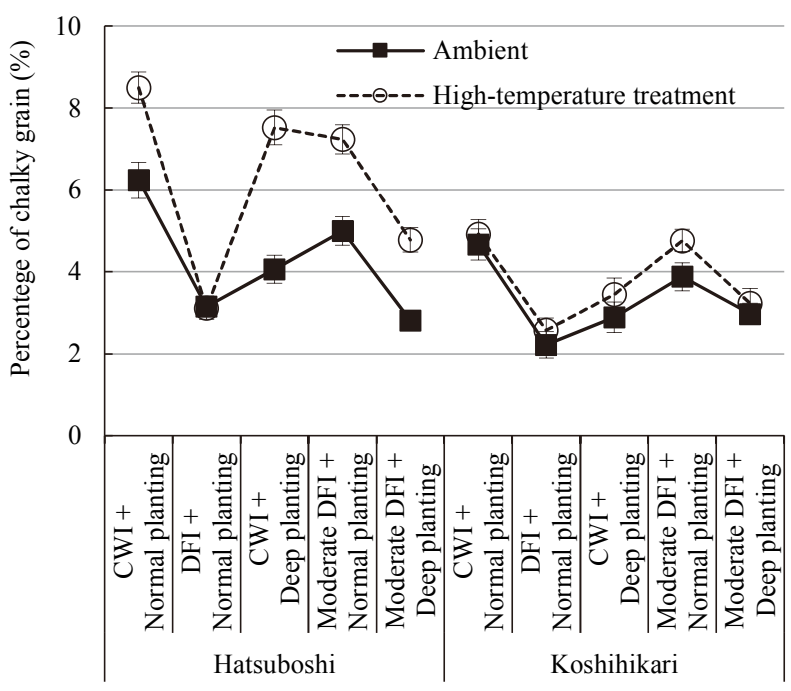

Fig. 9. Effect of the water management regime and planting depth on the percentage of chalky grains.

The average ambient temperature over 20 days after heading was $26.2^{\circ} \mathrm{C}$ at Hatsuboshi and $25.1^{\circ} \mathrm{C}$ at Koshihikari.The error bars represent the standard error. fore, we measured the penetration resistance in the paddy fields under CWI, DFI and moderate DFI at harvest. The penetration resistance under the DFI treatment was slightly less than that under the CWI treatment, although the differences were not significant (Fig. 11, Chiba et al. 2011b). The penetration resistance under all water management regimes was higher than $3.0 \mathrm{~kg} \mathrm{~cm}^{-2}$ — the standard soil bearing capacity required for combine harvesting (Ministry of Agriculture, Forestry and Fisheries 2013). This experiment was conducted in experimental paddy fields containing heavy

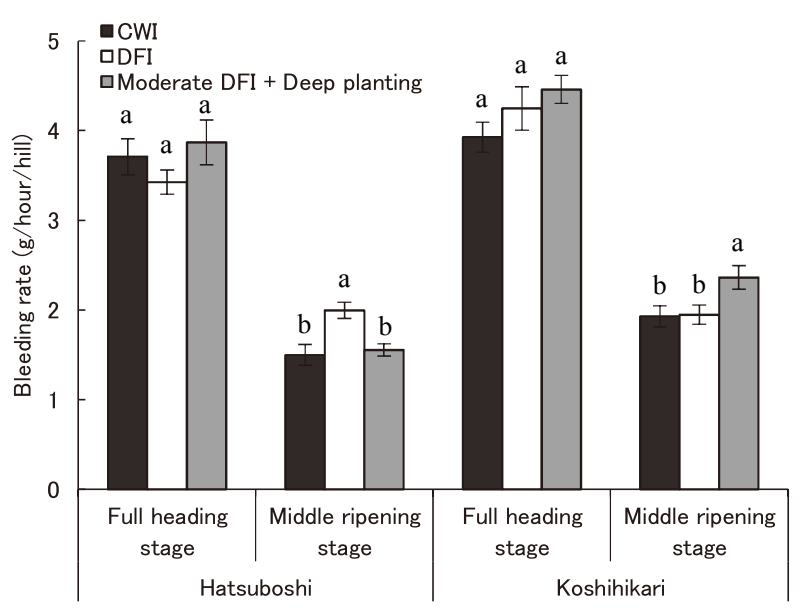

Fig. 10.Effect of the water management regime on the bleeding rate from the cutting section of tillers.

The same letter indicates no significant differences between the same cultivar and stage by Tukey's test $(\mathrm{P}<0.05)$. The error bars represent the standard error.

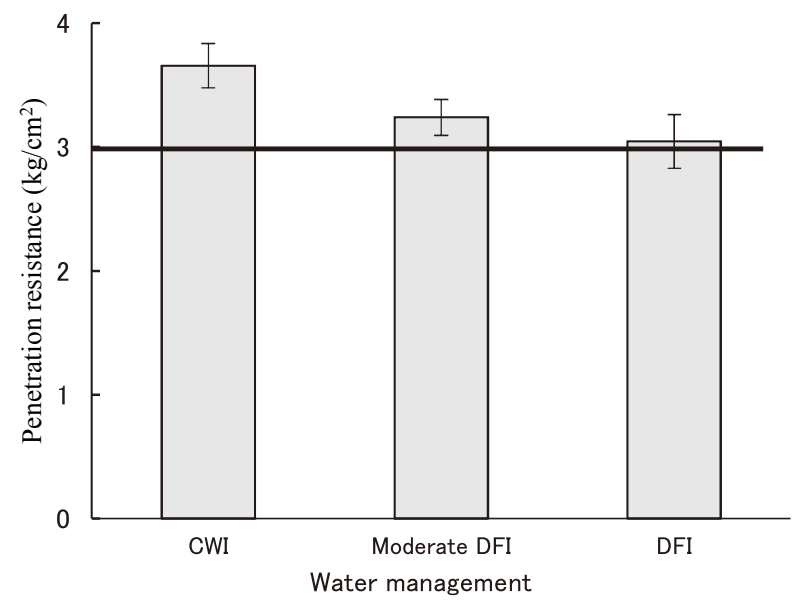

Fig. 11. Effect of the water management regime on the penetration resistance in a paddy field at harvest. The penetration resistance at a depth of $0-15 \mathrm{~cm}$ was investigated using a cone penetrometer DIK5521 (Daiki Rika Kogyo Co., Ltd., Saitama, Japan) and averaged. The line at $3 \mathrm{~kg} \mathrm{~cm}^{-2}$ represents the minimum resistance for machine harvesting. The error bars represent the standard error. 
clay soil. Even if this heavy clay presented poor drainage, the soil bearing capacity was still sufficient. Therefore, no problems should be seen with respect to root activity and field bearing capacity from the implementation of DFI, except in fields with exceptionally poor drainage.

\section{References}

Aichi Agricultural Research Center (2014) Technical manual of deep and permanent irrigation method for rice by the V-furrow no-till direct seeding. [In Japanese].

http://www.pref.aichi.jp/nososi/seika/gijutujohou/siryou/ fukamizu2.pdf

Arita, H. et al. (2006) Suitable paddy field system for deep ponding cultivation of rice. Study based on a survey of farmers and land improvement districts in a deep ponding water management implementation area. Trans of JSIDRE, 244, 125-131[In Japanese and English summary].

Chiba, M. et al. (2009) Improvement of grain quality and yield by deep-flood irrigation. Jpn. J. Crop Sci., 78, 455-464 [In Japanese and English summary].

Chiba, M. et al. (2011a) Mechanism of high quality rice production in deep-flood irrigation. Jpn. J. Crop Sci., 80, 13-20 [In Japanese and English summary].

Chiba, M et al. (2011b) Effect of deep planting and deep-flood irrigation on the yield and quality of rice. Jpn. J. Crop Sci., 80, 312-325 [In Japanese and English summary].

Chiba, M. et al. (2013) Deep-flood irrigation suppresses the occurrence of chalky grains through high source ability, in spite of the high percentage of secondary rachis grains. Jpn. J. Crop Sci., 82, 223-232 [In Japanese and English summary].

Chiba, M. \& Terao, T. (2014) Open-top chambers with solar-heated air introduction tunnels for the high-temperature treatment of paddy fields. Plant Prod. Sci., 17, 152-165.

Department of Agriculture, Forestry and Fisheries, Niigata Prefectural Government (2005) Guideline for cultivation of rice: 6 Management of paddy field.

http://www.maff.go.jp/j/seisan/kankyo/hozen_type/h_sehi_ kizyun/pdf/04180109 hondenkanri.pdf [In Japanese].

Department of Agriculture, Forestry and Fisheries, Shimane Prefectural Government (2015) Guideline for cultivation of rice, wheat, barley and soybean: Rice cultivation, II Cultivation techniques, 4 Preparation in paddy field and transplanting. http://www.pref.shimane.1g.jp/industry/norin/gijutsu/ nougyo_tech/kenyui/sisin_manyuaru/ine-sisin/ine-sisin. data/27.203.pdf [In Japanese].

Furuya et al. (1991) Effects of water management at middle growing stage on growth and yield of rice: Emphasis on deep water irrigation. Bull. Hokuriku Natl. Agric. Exp. Stn., 33, 29-53 [In Japanese].

ICPP (2013) Climate change 2013: The physical science basis. http://www.climatechange2013.org/images/report/
WG1AR5_ALL_FINAL.pdf

Ito, S., et al. (1970) Planting depth of transplanting cultivation using young rice seedling. Tohoku. Agric. Res., 11, 68-70 [In Japanese].

Kondo, M. et al. (2006) Effects of air temperature during ripening and grain protein contents on grain chalkiness in rice. Jpn. J. Crop Sci., 75 (Extra 2), 14-15 [In Japanese].

Matsui, T. (2009) Floret sterility induced by high temperatures at the flowering stage in rice (Oryza sativa L.). Jpn. J. Crop Sci., 78, 303-311. [In Japanese and English summary].

Ministry of Agriculture, Forestry and Fisheries (2013) Formulation and handling of introduction plan of the specific high-performance agricultural machine.

http://www.maff.go.jp/j/seisan/sien/sizai/s_kikaika/hosin/pdf/ guide_line.pdf

Miura, C et al. (2001) Difference of the reserved non-structuralcarbohydrate by tillering control of rice. Tohoku Agric. Res., 54, 45-46 [In Japanese].

Morita, S. (1999) How to measure and how to evaluate bleeding sap rate. Root Res., 8, 117-119 [In Japanese].

Morita, S. et al. (2002) Effect of high temperature on ripening in rice plants: Comparison of the effects of high night temperatures and high day temperatures (crop physiology and cell biology). Jpn. J. Crop Sci. 71, 102-109 [In Japanese and English summary].

Nagata, K. et al. (2004) Effect of air temperature during the early grain-filling stage on grain fissuring in rice. Jpn. J. Crop Sci., 73, 336-342 [In Japanese and English summary].

Ohe, M. et al. (2010) Effects of deep-flooding irrigation on growth, canopy structure and panicle weight yield under different planting patterns in rice. Plant Prod. Sci., 13, 193-198.

Resurreccion, A. P. et al. (1977) Effect of temperature during ripening on grain quality of rice. Soil Sci. Plant Nutri., 23,109-112.

Saito, Y. (1994) Growth of infant seedling with relation to transplanting depth. Hokuriku Crop Sci., 29, 62-63 [In Japanese].

Satake, T. et al. (1987) Male Sterility Caused by Cooling Treatment at the Young Microspore Stage in Rice Plants. XXVII. Effect of water temperature and nitrogen application before the critical stage on the sterility induced by cooling at the critical stage. Jpn, J. Crop Sci., 56, 406-410.

Satake, T. et al. (1988) Male sterility caused by cooling treatment at the young microspore stage in rice plants. XXVIII. Prevention of cool injury with the newly devised water management practices: Effects of the temperature and depth of water before the critical stage. Jpn. J. Crop Sci., 57, 234-241.

Tanaka, M. (1971) Studies on the deep layer placement of top-dressing fertilizer in rice production. Aomoriken nogyo shikenjo sougo gyoseki (Synthetic achievements of Aomori agricultural experimental station), 3, 1-389 [In Japanese].

Tashiro, T \& Ebata, M. (1975) Studies on white-belly rice kernel: IV. Opaque rice endosperm viewed with a scanning 
M. Chiba et al.

electron microscope. Proc. Crop Sci. Soc. Japan, 44, 205-214 [In Japanese and English summary].

Tashiro, T. \& Wardlaw, I.F. (1991) The effect of high temperature on kernel dimensions and the type and occurrence of kernel damage in rice. Aust. J. Agric. Res., 42, 485-496.

Toritsuka S. et al. (2013). Improvement of the rice grain quality in "Koshihikari" by deep flood-irrigation at the tillering stage along with the combination of fish production.

http://www.pref.shiga.lg.jp/g/nogyo/k_seika/23/files/07.pdf
[In Japanese].

Toyooka City Government. Agricultural practices to foster storks. http://www.city.toyooka.lg.jp/hp/genre/agriculture/ farming/guide.html [In Japanese].

Yoshino, Y. et al. (2007) The effect of top dressing at ear formation stage on brown rice on the quality and crude protein content of brown rice. Chiba Agric. Res. Cent., 6, 95-102 [In Japanese and English summary]. 